\title{
ENSINANDO TÉCNICAS DE RECICLAGEM, REUTILIZAÇÃO E REDUÇÃO DOS RESÍDUOS SÓLIDOS URBANOS PARA ALUNOS DO 4 ANO DO ENSINO FUNDAMENTAL, DA E.E.E.F. EDUARDO VARGAS EM ALEGRETE/RS
}

\author{
Melissa Fernandes Geraldo Mafaldo ${ }^{1}$, Damaris Kirsch Pinheiro ${ }^{2}$ \\ ${ }^{1}$ Especialista em Educação Ambiental - UFSM \\ ${ }^{2}$ Profa. Dra. (Professora/Orientadora do Curso de Especialização em Educação Ambiental e do \\ Departamento de Engenharia Química (DEQ-CT/UFSM). \\ melissamafaldo@gmail.com, damariskp@gmail.com
}

\section{RESUMO}

Este artigo é referente a monografia apresentada dia 31 de julho de 2010, no Curso de Pósgraduação em Educação Ambiental, intitulada Ensinando técnicas de reciclagem, reutilização $e$ redução dos resíduos sólidos urbanos, realizada com alunos do 4음 ano do ensino fundamental de 9 anos da Escola Estadual de Ensino Fundamental de Eduardo Vargas, de Alegrete - RS. O trabalho, realizado no período de março a junho de 2010, foi um projeto voltado para a área de educação ambiental, desenvolvido em âmbito escolar e que teve como foco educar, incentivar, sensibilizar e orientar alunos e as famílias sobre a problemática do lixo. O objetivo do mesmo era ensinar às crianças a seleção, reutilização, reciclagem de materiais e consequentemente a redução do lixo, através de técnicas e práticas sociais e pedagógicas que auxiliassem a compreensão da complexidade da relação homem x natureza e possibilitassem a visão holística que a educação ambiental promove sobre as sociedades. Sua justificativa estava na necessidade de se encontrar soluções para os resíduos sólidos urbanos e seu potencial poluidor. A metodologia do mesmo ocorreu em 10 dias de trabalho onde foram abordados diversos temas, desde separação do lixo, reciclagem, consumo consciente, etc. os alunos assistiram a vídeos, participaram de atividades lúdicas e pedagógicas e debateram o assunto, sendo que após cada período, foram avaliados multidicisplinarmente e convidados a expor seus trabalhos em mural-verdes. Sendo que ao fim foram obtidos ótimos resultados uma vez que a comunidade escolar, assim como a turma ficaram engajados e dispostos a trabalhar em prol da conscientização ambiental.

Palavras-chaves: resíduos sólidos urbanos, reciclagem, reutilização, redução, educação ambiental, conscientização e comunidade escolar. 


\section{INTRODUÇÃO}

As mudanças climáticas e os problemas ambientais e de saúde da atualidade fazem repensar certas atitudes e hábitos, antes banalizados, como, por exemplo, a destinação dos resíduos provenientes de nossas residências e locais de trabalho.

O problema dos resíduos sólidos urbanos atinge as mais diferentes nações. Algumas conseguem soluções eficientes para o seu tratamento, enquanto outras padecem com as inúmeras adversidades oriundas deste problema e que comprometem tanto a saúde da sociedade quanto da natureza. No Brasil, os problemas relacionados aos resíduos sólidos são inúmeros e, no entanto, apenas recentemente, sociedade e governo começaram a mobilizar-se para diminuir a geração dos mesmos ou trata-los de forma adequada, primeiramente diferenciando-os em seco ou orgânico e posteriormente em outras categorias de destinação.

Portanto, se antes o lixo, nome comumente dado aos resíduos sólidos, tinha uma destinação quase que exclusiva: das cidades para os depósitos ou lixões públicos ou jogado, abandonado em locais de pouca circulação, sem qualquer tipo de seleção, de reaproveitamento, agora o lema é reduzir, reciclar, reutilizar.

Assim, a Educação Ambiental deve ser considerada como a protagonista da necessária mudança de ordem comportamental das sociedades humanas. E é devido ao seu poder de sensibilização populacional que se realizou um projeto, descrito neste artigo, para promover o conhecimento das categorias de resíduos sólidos, suas formas de destinação, procedência, reciclagem, reaproveitamento e/ou reutilização e redução de materiais, tendo em vista a sustentabilidade do planeta e que teve por objetivo realizar atividades educativas e de conscientização ecológica, relacionados aos resíduos sólidos urbanos para alunos do 4ㅇa ano do fundamental, em uma escola da rede pública estadual, na cidade de Alegrete/RS.

\section{OBJETIVOS}

O objetivo principal deste trabalho foi promover a educação ambiental através da sensibilização para a política dos 3R's (reciclagem, reutilização e redução dos resíduos sólidos urbanos), com ações e práticas sociais e educativas e fazer da escola um ponto de coleta de materiais recicláveis e, principalmente, educar, incentivar, sensibilizar e orientar alunos e as famílias sobre a problemática do lixo para que buscassem soluções, tornando-se amigos e colaboradores do meio ambiente.

\section{REFERENCIAL TEÓRICO}

Estudos mostram um cenário futuro difícil para humanidade, relacionado aos atuais problemas ambientais ${ }^{1}$ e demonstram que para amenizar tais estimativas seria necessária a sociedade se reorganizar e desenvolver novas políticas e procedimentos para poder lidar com um mundo de recursos finitos (ODUM \& BARRETT, 2008).

A educação ambiental deve promover a transformação e a construção de novas perspectivas e conceitos para os indivíduos e a sociedade. Com ações individuais e coletivas,

\footnotetext{
${ }^{1}$ Problema ambiental: "situações onde há risco e/ou dano sócio-ambiental e não haja nenhum tipo de reação por parte dos atingidos diante do mesmo" (Carvalho \& Scotto, 1995).
} 
através de planejamento e cooperação ela busca o equilíbrio social, econômico, cultural, ecológico e ambiental, sempre objetivando formar cidadãos conscientes (Princípios da Educação Ambiental, 2009).

O contexto exposto na Lei de Educação Ambiental diz que ela deve ser integrante do processo educativo nacional e estar articulada em todos os níveis e modalidades de ensino, tanto formal quanto informalmente e interagir com o Sistema Nacional de Meio Ambiente, agindo em prol da conservação, recuperação e melhoria do meio ambiente e ainda cita a criação de ações e programas de gerenciamento de resíduos entre outros.

Quintas (2002) fala das experiências desenvolvidas pelos Núcleos de Educação Ambiental do IBAMA e que estas sugerem elementos para a capacitação dos educadores, tornando-os habilitados para atuar em sociedade em prol da qualidade do ambiente cita trabalhos com uma grande variedade de abordagens, entre os quais o lixo.

A Educação Ambiental deve propor que ao participar do processo coletivo de transformação da sociedade, a pessoa também estará se transformando. Desta forma, o processo educativo nacional deve estar estruturado para relacionar as diferentes áreas disciplinares com a sociedade e a gestão ambiental (QUINTAS, 2002).

No documento A Educação Ambiental na Construção da Escola Democrática e Popular (Secretaria da Estadual de Educação / RS) está exposto que nas escolas estaduais o trabalho com as questões ambientais deve priorizar a realidade dos estudantes e da comunidade, tendo a mesma como foco de sua metodologia de construção social, onde caracterizam-se os currículos articulados e a participação coletiva nas propostas socioambientais locais.

Há a necessidade de aquisição de conhecimentos e habilidades que permitam o efetivo envolvimento e comprometimento das pessoas com a causa ambiental de forma transparente e humilde, cabendo à Educação Ambiental promover a mudança comportamental das pessoas em sua relação cotidiana e individual com o meio ambiente sobre hábitos ambientalmente corretos no meio social (QUINTAS, 2002).

A complexidade da questão ambiental cria a necessidade da existência de processos educativos com conhecimentos e metodologias específicas para o desenvolvimento da habilidade e da aprendizagem de crianças, jovens e adultos em contextos socioambientais, a fim de desenvolver cada vez mais atitudes participativas na resolução dos problemas ambientais (QUINTAS, 2002).

Moura (2001) destaca a necessidade de efetivas e mediadoras políticas públicas de educação e de meio ambiente, por um amplo conjunto de ações de desenvolvimento social, econômico, cultural e ambiental.

O Artigo 225 da Constituição Federal (BRASIL, 1988) ao mesmo tempo em que estabelece "o meio ambiente ecologicamente equilibrado" como direito e como bem de uso comum do povo e essencial à qualidade de vida, também impõe ao Poder Público e a coletividade o dever de defendê-lo e preservá-lo para que as futuras gerações possam dele usufruir.

Segundo Quintas (2002), as ações da sociedade têm capacidade variada de influenciar direta ou indiretamente na transformação da qualidade ambiental ${ }^{2}$, sendo que a escola tem poder de incidir diretamente na opinião pública e ter grande repercussão no meio ambiente e na qualidade de vida das populações.

\footnotetext{
${ }^{2}$ Qualidade ambiental: "condições limitantes da qualidade ambiental, muitas vezes, expressas em termos numéricos, usualmente estabelecidos por lei e sob jurisdição específica, para proteção da saúde e do bem-estar dos homens" (Moreira, 1990).
} 
Quintas (2002) cita o lixo como uma das ocorrências que põe em risco a integridade dos ecossistemas e que interferem negativamente na qualidade de vida das populações e expõe que não é possível a prática da gestão ambiental sem a presença do Estado, ao qual não se permitem omissões e eventuais conivências, e da sociedade civil, que não pode ser desinteressada ou indiferente aos problemas ambientais e que ambas devem trabalhar compartilhadamente e com objetivos comuns.

A responsabilidade social deve ser vista como fator crucial para a disseminação de qualquer técnica ou conhecimento sobre educação ambiental, inclusive no que se refere a destinação de resíduos sólidos, tanto por parte das empresas quanto por parte dos cidadãos (QUINTAS, 2002).

Odum e Barret (2008) ressaltam que a gestão dos ecossistemas é um desafio para o futuro, devendo-se abordar econômica e tecnologicamente os complexos problemas que a cada ano ficam mais evidentes e que tanto as sociedades naturais como as humanas funcionam da mesma maneira. A gestão dos chamados ecossistemas humanos utiliza-se de indicadores sociais e biológicos e é a abordagem que serve para resolver os problemas ambientais mundiais. Desta forma, todos os tipos de resíduos e poluentes são considerados parte dos ecossistemas, uma vez que são energias dos ambientes de saída destes.

Assim, além de um problema ambiental, os resíduos sólidos tornaram-se graves problemas sociais, gerados por um conjunto de processos urbanos e, como tais, não se encontram alheios à vida social humana, mas são completamente penetrados e reordenados por ela, confundindo atualmente o que é "natural" com o que é "social". (FREITAS, 2003).

Segundo Rodrigues e Cavinatto (2002), a palavra lixo deriva de lix, que em latim significa "cinza", daí sua definição de sujeira, coisas inúteis, velhas. No entanto, tecnicamente é sinônimo de resíduos sólidos, ou seja, materiais descartados pelo homem.

Nos últimos séculos, a população mundial dobrou, mas a produção de lixo aumentou numa proporção muito maior. Então, a questão atual é: o que fazer com tanto lixo? o problema é seriíssimo, principalmente com relação ao ambiente, porém, tem solução: a separação e a destinação correta dos resíduos e a diminuição de acúmulo de resíduos, de desperdício de materiais e de consumo em excesso (RODRIGUES \& CAVINATTO, 2002).

Segundo Rodrigues e Cavinatto (2002), a população brasileira, assim como as demais subdesenvolvidas, não se sente responsável pelo lixo que produz, ao contrário do primeiro mundo onde existe uma consciência ecológica maior.

O Artigo 54 da Lei de Crimes Ambientais (BRASIL, 1998) cita o lançamento de resíduos sólidos ou detritos, óleos e substância semelhantes como exemplos do crime supracitado.

O lixo urbano tornou-se um grande problema, principalmente nos grandes centros urbanos onde são depositados nas ruas, se acumulam e, durante as chuvas, dificultam a drenagem urbana, negligência tanto dos populares quanto dos administradores (RODRIGUES \& CAVINATTO, 2002).

$\mathrm{Na}$ era dos descartáveis, marcada por produtos de menor durabilidade e milhões de embalagens, principalmente de alimentos e bebidas, utilizadas diariamente, aumentou consideravelmente a quantidade de lixo que, aliás, serve para analisar o modo de vida de cada comunidade. Os países desenvolvidos tendem a acumular lixo com componentes eletrônicos, como televisores e computadores, plásticos, alumínio e derivados de papel, enquanto que os subdesenvolvidos têm no lixo grandes quantidades de materiais orgânicos, ou seja, restos de comida. No entanto, tem que se ressaltar a tendência mundial em reaproveitar os resíduos, 
modificando o conceito anterior de lixo, através dos processos de reciclagem, produzindo novos materiais e economizando matéria-prima e energia (RODRIGUES \& CAVINATTO, 2002).

A relação entre resíduos e problemas ambientais é mais evidente no campo dos resíduos sólidos, uma vez que seu grau de dispersão é bem menor do que o dos líquidos e gasosos. Por isso, é fácil ter uma ideia da dimensão do problema, imaginando as quantidades de lixo produzidas em cada casa ou em cada unidade industrial e que, de alguma forma, devem ser dispostas (DEMAJOROVIC, 1995).

Os resíduos sólidos podem ser divididos em vários grupos (NBR 10.004/04):

- Quanto às características físicas:

- Seco: papéis, plásticos, metais, couros tratados, tecidos, vidros, madeiras, guardanapos e tolhas de papel, pontas de cigarro, isopor, lâmpadas, parafina, cerâmicas, porcelana, espumas, cortiças.

- Molhado: restos de comida, cascas e bagaços de frutas e verduras, ovos, legumes, alimentos estragados, etc...

- Quanto a composição química:

○ Orgânico: restos alimentares, de plantas, de animais, etc.

- Inorgânico: composto por vidros, metais, etc.

- Quanto a origem:

- Doméstico; produzido nas residências formado por embalagens de comida e bebidas e materiais biodegradáveis (restos alimentícios e higiênicos);

- Comercial e Industrial: basicamente papel, papelão e resíduos dos processos de fabricação;

○ De fontes especiais: lixo nuclear, restos de agrotóxicos e hospitalares.

Segundo Rodrigues \& Cavinatto (2002), grande parte dos resíduos sólidos, gerados nos centros urbanos, são compostos de materiais recicláveis, que através de bons e eficientes sistemas de coleta seletiva e reciclagem geram lucros as empresas e trabalhadores e deixam de poluir ambientes. Todavia, nem tudo que é descartado pode ser reaproveitado, como, por exemplo, algumas embalagens, materiais contaminados (seringas, papel higiênico, guardanapos de papel, fraldas, etc) e objetos pessoais (escova de cabelo, tênis, guarda-chuva, caneta, etc.), sendo que os rejeitos variam conforme a sua origem.

Odum \& Barrett (2008, p.461) dizem que "futuramente será necessário definir o autointeresse em termos de sobrevivência e em vez de consumo" e que a redução do desperdício atual e a eficiência na realização de atividades para consumir menos energia e diminuir a perda de recursos naturais é algo que deve ter início imediato, diante do cenário atual da sociedade.

Segundo Quintas (2002, p.122), adotando-se a filosofia do "cada um fazer a sua parte" deixa-se implícita a ideia que isto solucionaria parte dos problemas ambientais existentes. De modo que, ao consumir apenas o necessário e reaproveitar ao máximo os produtos utilizados, transformando rejeitos em coisas úteis, se conseguiria economizar recursos naturais e energia, minimizando impactos ambientais negativos.

Segundo Rodrigues \& Cavinatto (2002), o descarte inadequado do lixo, ou seja, o descarte sem tratamento causa danos ambientais relacionados ao solo, água e ao ar, alterando suas características químicas, físicas e biológicas, além da formação gases tóxicos pela decomposição dos resíduos no meio, além de promover a reprodução de roedores e insetos como moscas, mosquitos e baratas. 
A redução da quantidade de lixo pode ser alcançada com a diminuição do consumo doméstico, a reciclagem e a reutilização, sendo que estas alternativas levam a poupar energia e materiais, importantes passos para a preservação ambiental (RODRIGUES \& CAVINATTO, 2002).

Os 3Rs do lixo, como são conhecidas a reciclagem, a reutilização e a redução, têm como principal objetivo a diminuição da produção de resíduos sólidos e a preservação dos recursos naturais e do meio ambiente. A redução consiste em diminuir o consumo de determinados materiais, principalmente os derivados de recursos naturais não renováveis como, por exemplo, isopor, enquanto que a reciclagem utiliza materiais usados para produzir novos produtos. Já a reutilização significa usar um produto de várias maneiras (RODRIGUES \& CAVINATTO, 2002).

Quando se trabalha a questão do lixo em Educação Ambiental, deve-se enfatizar a ação individual por meio dos três R (reduzir, reutilizar e reciclar), na perspectiva do "lixo que não é lixo", contestando o consumismo e o desperdício (QUINTAS, 2002).

Segundo Rodrigues e Cavinatto (2002), a coleta seletiva é baseada na separação de materiais que são jogados fora. Através dela, os caminhões descarregam, na usina, plásticos, papéis, papelões, vidros e latas para o reaproveitamento. O processo pode ser iniciado em qualquer casa ou instituição que assim resolva colaborar com o meio ambiente. Ainda há coleta individual nas ruas, geralmente feita por pessoas desempregadas ou em situação de miséria, que sobrevivem disto, uma vez que o comércio de sucata movimenta grandes valores no país.

Ressalta-se que, para a coleta seletiva realmente funcionar, é necessária uma adequada infraestrutura para armazenar e comercializar os produtos com as usinas de reciclagem, sendo que o armazenamento poderia ser feito em grandes recipientes, principalmente, nos ambientes escolares. No entanto, no Brasil infelizmente apenas $10 \%$ das cidades tem coleta seletiva, sendo que a maior parte dos materiais que poderia ser reciclado ainda não o é. $O$ aspecto principal da implantação de programas dessa natureza deve-se a trabalhos educacionais que mobilizam alunos e comunidade em prol de objetivos sociais, econômicos e ambientais da reciclagem, ampliando cada vez mais o nível de conscientização (RODRIGUES \& CAVINATTO, 2002).

Elementos químicos, madeira, petróleo, alimentos, provêm da natureza e possuem um ciclo de vida ou disponibilidade natural e, após beneficiados e utilizados, são descartados e se acumulam como lixo ou esgoto. Desta forma, a reciclagem preserva os recursos naturais, poupando energia, diminuindo sua extração e seu acúmulo nos centros urbanos, economia para o país, para as pessoas e para a natureza (RODRIGUES \& CAVINATTO, 2002).

Aguiar (1996) sugestiona a reciclagem e a reutilização como formas de promover o desenvolvimento sustentável.

A reciclagem transforma diversos tipos de materiais em matéria-prima para outros produtos, não importando se estão amassados, rasgados, acabam compondo novos objetos, sendo que os rejeitos variam conforme a origem, como já foi dito, os hábitos da população e a sazonalidade de alguns. Diante desta nova perspectiva, aumenta o número de entidades, como prefeituras e escola, preocupadas e interessadas em trabalhar / selecionar seus resíduos (RODRIGUES \& CAVINATTO, 2002).

Segundo Rodrigues \& Cavinatto (2002), a decomposição das substâncias orgânicas ocorre em qualquer ambiente onde se encontrem bactérias e fungos, tanto numa lixeira, quanto num aterro ou numa composteira. No entanto, quando o lixo está muito compactado, em vez da forma aeróbica, que é mais completa e resulta em dióxido de carbono - $\mathrm{CO}_{2}$, vapor d'água e sais minerais, ocorre a decomposição anaeróbica que gera diversos subprodutos tóxicos, como o metano e o gás sulfídrico. Além disto, a decomposição anaeróbica produz um líquido escuro 
chamado chorume ${ }^{3}$, que é extremamente tóxico e capaz de contaminar o solo e as águas subterrâneas.

A NBR 13.591/96 define compostagem como:

Processo de decomposição biológica da fração orgânica biodegradável dos resíduos, efetuado por uma população diversificada de organismos, em condições controladas de aerobiose e demais parâmetros, desenvolvido em duas etapas distintas: uma de degradação ativa e outra de maturação.

Segundo a Resolução nำ275/01 do CONAMA, para a separação do material, basta ter em casa dois recipientes: um para o lixo úmido e outro recipiente para o reciclável. No caso de condomínios, escolas ou empresas podem-se aumentar o número de recipientes destinados à coleta seletiva, identificando-os por cores e tipos de material:

- $\quad$ Azul-Papel;

- Verde - Vidro;

- $\quad$ Amarelo - Metal (alumínio e metais ferrosos);

- Vermelho - Plástico;

- Marrom - Orgânico (restos de alimentos ou podas de árvores que podem ser transformados em adubo);

- Branco - Materiais hospitalares ou contaminados;

- $\quad$ Cinza - Rejeito (material sujo e/ou que não serve para a reciclagem).

\section{MATERIAIS E MÉTODOS}

O trabalho foi realizado com 31 crianças do 4ㅇa ano do ensino fundamental de 9 anos da E.E.E.F. Eduardo Vargas, no período de março a junho de 2010, sendo que as atividades aconteciam as terças e quintas-feiras, das $16 \mathrm{~h}$ as $17 \mathrm{~h} 15 \mathrm{~m}$, totalizando $12 \mathrm{~h} 30 \mathrm{~m}$.

Com a finalidade de promover a cidadania consciente através de práticas educativas que visassem ensinar a reciclagem, a reutilização e o descarte correto dos resíduos sólidos urbanos, o projeto abordou tópicos como consumo consciente, impactos ambientais, sacolas retornáveis, separação do lixo, coleta seletiva, exercício de cidadania e aspectos da reciclagem, reutilização e redução dos resíduos sólidos urbanos.

Entre as atividades propostas estavam: aplicação de dinâmicas, oficinas, palestras, construção de ponto de coleta (com lixeiras identificadas conforme o fim a que se destinam), estudo do lixo, vídeos e outras mídias educacionais.

Já entre os materiais utilizados estão jogos educacionais (dominó, memória, quebracabeças), brincadeiras (colocar o lixo no lugar certo), materiais didáticos (relacione as colunas, desenhos para pintar, trabalhando com conjuntos, jogo dos sete erros, caça-palavras, questionários, responda, cite, etc.).

Após cada dia de atividade os alunos eram avaliados através de textos e debates, que foram expostos em mural-verdes criados por eles e que, posteriormente, serviram de espaço de conhecimento e de divulgação do trabalhos realizados.

\footnotetext{
${ }^{3}$ Líquido residual do lixo, formado por um misto de água e restos orgânicos, é extremamente poluente (Rocha, 1992)
} 


\section{Monografias Ambientais (e-ISSN: 2236-1308)}

REMOA

\section{RESULTADOS E DISCUSSÕES}

Os alunos participaram ativamente do projeto, faziam perguntas e estavam sempre dispostos a ouvir.

À medida que se os trabalhos foram sendo realizados observou-se cada vez mais interação dos educando com a conscientização proposta, centrada no exercício da cidadania e na reformulação de valores éticos e morais, individuais e coletivos, numa perspectiva orientada para o desenvolvimento sustentável. Este fato pode ser comprovado através das pesquisas feitas, respectivamente, no início e no meio do andamento dos trabalhos:

1ํㅗ Pesquisa - realizada antes do início das atividades.

\begin{tabular}{|c|c|c|}
\hline Você joga lixo no chão? & № & $\%$ \\
\hline Sim & 13 & 41,94 \\
\hline Não & 18 & 58,06 \\
\hline Total & 31 & 100,00 \\
\hline O que você faz se ver alguém jogando lixo no chão? & № & $\%$ \\
\hline Nada & 18 & 58,06 \\
\hline Junta & 12 & 38,71 \\
\hline Fala pra pessoa que é errado & 1 & 3,23 \\
\hline Total & 31 & 100,00 \\
\hline Você sabe o que é reciclagem? & № & $\%$ \\
\hline Sim & 16 & 51,61 \\
\hline Não & 12 & 38,71 \\
\hline Talvez & 3 & 9,68 \\
\hline Total & 31 & 100,00 \\
\hline Você sabe o que é coleta seletiva? & № & $\%$ \\
\hline Sim & 15 & 48,39 \\
\hline Não & 12 & 38,71 \\
\hline Talvez & 4 & 12,90 \\
\hline Total & 31 & 100,00 \\
\hline Na sua casa o lixo é separado? & № & $\%$ \\
\hline Sim & 5 & 16,13 \\
\hline Não & 23 & 74,19 \\
\hline Talvez & 3 & 9,68 \\
\hline Total & 31 & 100,00 \\
\hline Você sabe como separar o lixo? & № & $\%$ \\
\hline Sim & 19 & 61,29 \\
\hline Não & 5 & 16,13 \\
\hline Talvez & 7 & 22,58 \\
\hline Total & 31 & 100,00 \\
\hline Você faz alguma coisa para colaborar com o meio ambiente? & № & $\%$ \\
\hline Sim & 10 & 32,26 \\
\hline
\end{tabular}


REMOA

\begin{tabular}{|c|c|c|}
\hline Não & 12 & 38,71 \\
\hline Talvez & 9 & 29,03 \\
\hline Total & 31 & 100,00 \\
\hline Fonte: Melissa Mafaldo & & \\
\hline 2ㅁ Pesquisa - realizada após o 4 o dia de atividades & & \\
\hline Você joga lixo no chão? & № & $\%$ \\
\hline Sim & 0 & 0,00 \\
\hline Não & 31 & 100,00 \\
\hline Total & 31 & 100,00 \\
\hline O que você faz se ver alguém jogando lixo no chão? & № & $\%$ \\
\hline Nada & 0 & 0,00 \\
\hline Junta & 0 & 0,00 \\
\hline Fala pra pessoa que é errado & 31 & 100,00 \\
\hline Total & 31 & 100,00 \\
\hline Você sabe o que é reciclagem? & № & $\%$ \\
\hline Sim & 31 & 100,00 \\
\hline Não & 0 & 0,00 \\
\hline Talvez & 0 & 0,00 \\
\hline Total & 31 & 100,00 \\
\hline Você sabe o que é coleta seletiva? & № & $\%$ \\
\hline Sim & 31 & 100,00 \\
\hline Não & 0 & 0,00 \\
\hline Talvez & 0 & 0,00 \\
\hline Total & 31 & 100,00 \\
\hline Na sua casa o lixo é separado? & № & $\%$ \\
\hline Sim & 29 & 93,55 \\
\hline Não & 0 & 0,00 \\
\hline Talvez & 2 & 6,45 \\
\hline Total & 31 & 100,00 \\
\hline Você sabe como separar o lixo? & № & $\%$ \\
\hline Sim & 30 & 96,77 \\
\hline Não & 0 & 0,00 \\
\hline Talvez & 1 & 3,23 \\
\hline Total & 31 & 100,00 \\
\hline Você faz alguma coisa para colaborar com o meio ambiente? & № & $\%$ \\
\hline Sim & 29 & 93,55 \\
\hline Não & 0 & 0,00 \\
\hline Talvez & 2 & 6,45 \\
\hline Total & 31 & 100,00 \\
\hline
\end{tabular}


A ludicidade com que as atividades foram apresentadas fez com que os alunos aprendessem "brincando" sobre ações cidadãs de percepção e tratamentos dos resíduos sólidos urbanos e dos problemas ambientais por ele gerados.

Em suas narrativas passaram a falar sobre o que havia mudado em suas casas e na escola, e sobre o que faziam de errado e de correto com relação ao lixo.

"Antes a mãe não sabia como era importante para a natureza separar o lixo de casa, agora ela separa - Aluno A."

"Aprendi a separar o lixo, a ser mais consciente, que não se deve jogar o lixo no chão, que todo mundo deve cuidar da natureza, porque nos precisamos dela e os animais também. Que podemos economizar água e luz e que podemos transformar o lixo ou aquilo que se acha lixoAluno B"

Mas a proposta evoluiu mesmo quando a turma montou na escola um ponto de coleta seletiva, estendido a comunidade, onde catadores locais podiam recolher os materiais. A partir deste momento a comunidade ficou engajada e a cada dia busca novas propostas para melhorar a qualidade ambiental.

"Aprendi a reciclar materiais, faço brinquedos, junto potes, desligo a luz, não tomo banho demorado. É muito importante separar o lixo e fazer a compostagem, isso evita os lixões, doenças e problemas para a natureza. Toda família deve participar e ser cidadão - Aluno C".

"Reciclando a gente economiza madeira, areia, petróleo, as árvores e a água. Quando se é consciente gasta menos e economiza dinheiro - Aluno D".

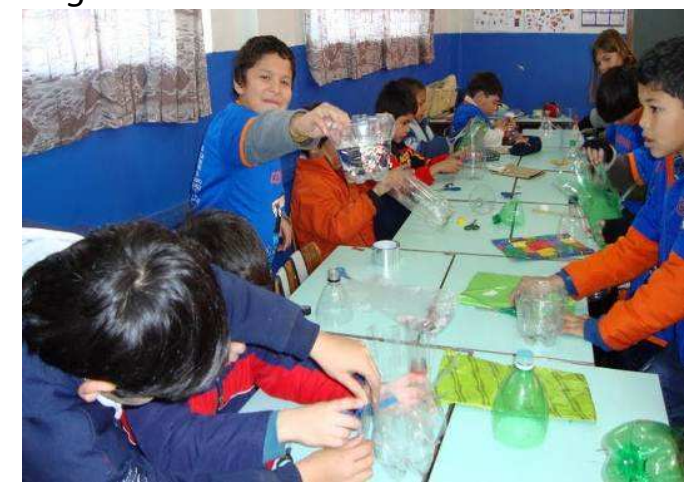

Figura 01. Aula de reciclagem de materiais 20/04. Fonte: Melissa Mafaldo

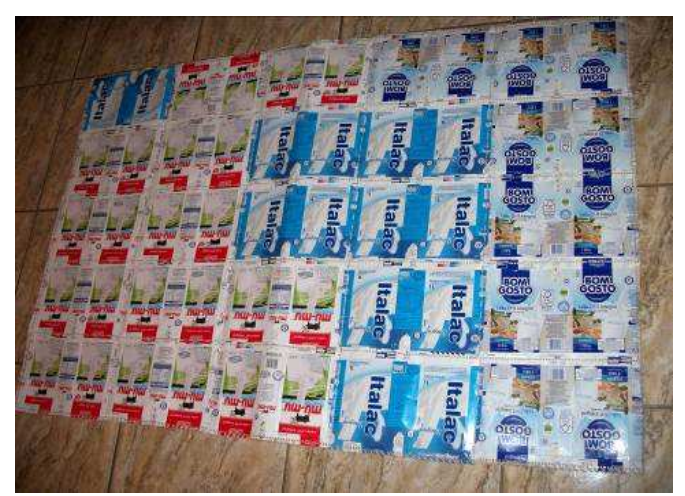

Figura 3. Detalhes do material utilizado para confeccionar os murais-verdes - caixas de leite. Fonte: Melissa

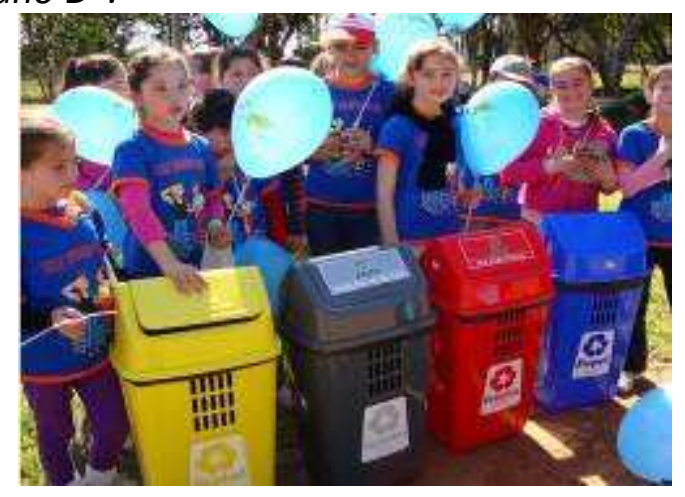

Figura 02. Alunos com os novos recipientes de coleta seletiva, patrocinados por uma empresa local. Fonte: Melissa Mafaldo

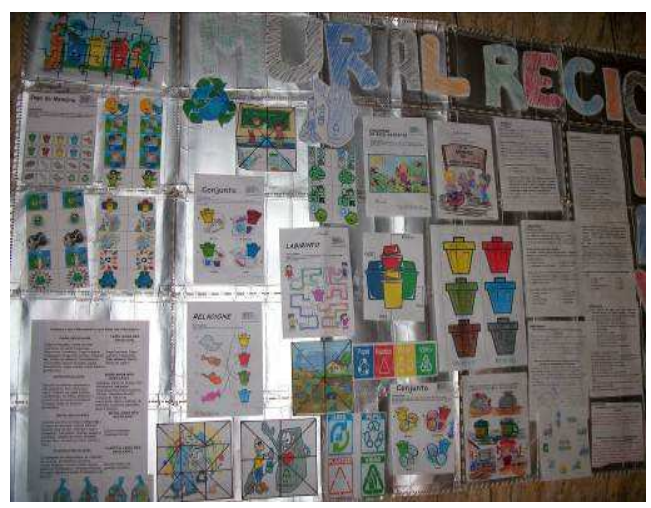

Figura 04. Detalhes do mural-verde utilizado na defesa da monografia. Fonte: Melissa Mafaldo 


\section{CONCLUSÕES}

Sabe-se que o equilíbrio dos ecossistemas depende de como a ação antrópica age sobre eles.

A educação ambiental deve ser prioridade tanto para governos como para sociedades civis, pois aos governos cabe destinar mais recursos financeiros ao saneamento básico e aos planos gestores das cidades, que se ocupem das questões ambientais, mas, principalmente, cabe a indivíduo, no seu papel de agente e de parte da natureza, modificar seus hábitos e atitudes em prol da preservação dos recursos naturais, pois a única forma de se garantir a manutenção da qualidade de vida no planeta é o homem agir de forma ambiental e ecologicamente correta.

Desta forma, considerando-se que o objetivo principal deste trabalho foi promover a EA através da sensibilização para a política dos 3R's (reciclagem, reutilização e redução dos resíduos sólidos urbanos), com ações e práticas sociais e educativas, pode-se dizer que o mesmo foi alcançado com êxito, pois ao abordar-se as questões ambientais conforme a realidade dos estudantes e da comunidade e das problemáticas socioambientais locais, fez-se com que todos, alunos e famílias, fossem estimulados a contribuir tendo em vista que vivenciaram as melhorias de suas ações.

Ao trabalhar-se o objetivo principal sob o ponto de vista da relação sociedade-natureza, correlacionando a problemática ambiental entre os meios social e físico-natural e realizando práticas do meio social, facilitou-se positivamente a compreensão dos indivíduos envolvidos sobre a qualidade do meio ambiente, alcançando-se também o objetivo de orientar os alunos para a cidadania consciente.

Ao considerar-se a importância do direito a informação, garantiu-se o objetivo de educar os alunos para a separação adequada dos resíduos sólidos, uma vez que é através da informação que os indivíduos tem a opinião formada a respeito do meio ambiente, seus problemas e os métodos preventivos.

A aquisição de informações promovida pela EA, democraticamente transforma os indivíduos em "donos" da natureza, dando-lhes o conhecimento necessário para desenvolver competências e habilidades sobre o assunto, pois uma vez que se conhecem problemas, técnicas e os benefícios dos recursos naturais, assim como as relações de dependência entre eles e as sociedades, torna-se mais fácil se trabalhar em prol da sua proteção, preservação e restauração, neste fato garantiu-se o objetivo de incentivar a reciclagem dos materiais orgânicos domésticos, através da compostagem.

Ao acreditar-se que a transmissão de conhecimentos acerca da importância da participação da comunidade na escola e vice-versa promove o comprometimento de todos no processo educativo e na construção e transformação social em prol meio ambiente faz com o objetivo de fazer da escola um ponto de coleta de materiais recicláveis tenha sido plenamente alcançado.

A escolha do tema impulsionou a necessidade de entender, ampliar e, acima de tudo, vivenciar esses princípios nas práticas sociais e pedagógicas cotidianas, assim ao promover a destinação correta dos resíduos sólidos urbanos, portanto almejou-se e conquistou-se a sensibilização do público-alvo para as questões ambientais, em especial para a contaminação pelo lixo;

Assim, deve-se ter em mente que a educação ambiental precisa conquistar cada vez mais legitimidade, visibilidade e espaço público para se solidificar e ampliar sua perspectiva filosófica e política comprometida com sustentabilidade, ética, justiça social, cidadania, autonomia, responsabilidade e liberdade. 
Portanto, a EA deve estar atenta aos movimentos do cotidiano que refletem outras formas de participação cidadã entre diferenças e singularidades da complexa relação de interdependência entre homem e natureza. Pois é a diversidade, aparentemente frágil, que quando se junta em algum espaço/tempo, fortalece e legitima propostas, afirmativas, possibilidades e alternativas que considerem o foco da educação ambiental como sendo a manutenção, a reparação e a sobrevivência do meio em que se vive.

\section{REFERENCIA BIBLIOGRÁFICA}

AMBIENTE BRASIL. Resíduos Sólidos Urbanos In: Site Ambiente Brasil. Disponível em: <http://www.ambientebrasil.com.br/composer.php3?base=residuos/ index.php3\&conteudo=./residuos/residuos.html $>$, acessado em setembro/09.

ABNT - Associação Brasileira de Normas Técnicas. Classificação de Resíduos Sólidos - NBR 10.004/04. Disponível em: < http://www.aslaa.com.br/legislacoes /NBR\%20n\%2010004-2004.pdf>, acessado em maio/2010.

Compostagem - NBR 13.591/96. Disponível em: < http://sugestoes-

pontoorg.blogspot.com/2007/06/algumas-definies.html>, acessado em maio/10

AGUIAR, R.A.R. Direito do meio ambiente e participação popular. Brasília: IBAMA, 1996.

BRASIL. Constituição da República Federativa do Brasil. Brasília: Senado Federal, 1988.

. Lei no9.795 de 1999. Dispõe sobre a Política Nacional de Educação Ambiental. Disponível em:

<http://www.planalto.gov.br/ccivil/Leis/L9795.htm>, acessado em maio/2010.

. Lei no9.605 de 1998. Dispõe sobre os Crimes Ambientais. Disponível em: <

http://www.planalto.gov.br/ccivil_03/Leis/L9605.htm>, acessado em maio/2010.

CONAMA. Resoluções CONAMA de 1984 a 2001. Brasília, 2010. Disponível em:

<http://www.mma.gov.br/port/conama/legiano.cfm?codlegitipo=3>, acessado em 31/03/10.

DEMAJOROVIC, J. Da política tradicional à de tratamento do lixo à política de gestão de resíduos sólidos. Revista de administração de empresas. São Paulo. 1995.

ECOLNEWS. Reciclagem. Disponível em: <http://www.ecolnews.com.br/lixo.htm>, acessado em setembro/09.

FREITAS, C.M. Problemas ambientais, saúde coletiva e ciências sociais. São Paulo, SP: Editora Moderna. Ciências e saúde coletiva. 2003.

MMA - Ministério do Meio Ambiente. AGENDA 21. Integral para Consulta On-Line. Disponível em: http://www.mma.gov.br/port/SE/agen21/agint.html, acessado em 25 abr. 2010.

. Salas Verdes. Disponível em:

http://www.mma.gov.br/sitio/index.php?ido=conteudo.monta\&idEstrutura=20\&idConteudo=3634\&idMenu=1138, acessado em 26 abr. 2009.

Programa Nacional de Meio Ambiente. Disponível em:

http://www.br.geocities.com/ambientche/fnma.htm, acessado em 14 maio 2009.

MOURA, C,I. Qual educação ambiental? Elementos para um debate sobre educação ambiental e extensão rural. Agroecologia e Desenvolvimento Rural Sustentável. Porto Alegre, v.2, n.2, abr./jun.2001 


\section{Monografias Ambientais $\quad(e-I S S N$ : 2236-1308)}

\section{REMOA}

ODUM, E.P.; BARRETT, G.W. Fundamentos de Ecologia - Tradução da 5a edição norte-americana. [tradução Pégasus Sistemas e Soluções]. São Paulo, SP: Cengage Learning, 2008.

QUINTAS, J.S. Introdução à Gestão Ambiental Pública. 1ạ ed - Brasília, DF: SCEN. 5ạ Série Educação Ambiental, Coleção Meio Ambiente. Ministério do Meio Ambiente: Coordenação Geral de Educação Ambiental. IBAMA - Instituto Brasileiro do Meio Ambiente e dos Recursos Naturais Renováveis. 2002.

RECICLOTECA - Centro de Informações sobre Reciclagem e Meio Ambiente. Disponível em:

<http://www.recicloteca.org.br/Default.asp>, acessado em 12/03/10;

REIGOTA, M. Meio ambiente e representação social. 4ạ Ed. - São Paulo, Cortez Editora - Coleção questões da nossa época; v.41. 2001.

RIO GRANDE DO SUL. Secretaria da Educação. Departamento Pedagógico. Política de Educação Ambiental. A Educação Ambiental na Construção da Escola Democrática e Popular. 1a ed - Porto Alegre, RS: Secretaria Estadual de Educação/RS, 2002.

ROCHA, A.J.A.; NAVES, M.A.; CRUZ E SOUZA, J. Guia do Meio Ambiente: coletânea de temas. Brasília: Tablóide, 1992.

RODRIGUES, F.L.; CAVINATTO, V.M. Lixo: De onde vem? Para onde vai? Coleções Desafios. 7ạ Edição. São Paulo: Editora Moderna, 1997.

TAVARES, M, G; MARTINS, E, F; GUIMARÃES, E F. Educação ambiental, estudo e intervenção do meio. OEI-Revista Iberoamericana de Educación (ISSN: 1681-5653). 2001.

UNIVERSIDADE FEDERAL DE SANTA MARIA. Centro de Ciências Rurais. Pós-graduação em Educação Ambiental. Disciplina de Educação Ambiental. Princípio da Educação Ambiental. Santa Maria, RS, 2009. Pdf, p.01-02. 